$\xi=\Phi$

\title{
Socio-economic factors and child health status in Ghana
}

\author{
Mustapha Immurana ${ }^{1 *}$, Arabi, U. ${ }^{2}$ \\ ${ }^{1}$ Research Scholar, Department of Economics, Mangalore University, Mangalagangotri - 574119, Karnataka State, India \\ ${ }^{2}$ Professor and Research Guide, Department of Economics, Mangalore University, Mangalagangotri - 574119, Karnataka State, India \\ *Corresponding author E-mail: mustaphaimmurana@gmail.com
}

\begin{abstract}
Ghana's under-five mortality rate far exceeds the Sustainable Development Goal (SDG) 3.2 Target of 25 deaths per thousand live births by 2030 . Therefore to improve upon the situation, it is imperative that the factors which determine the health status of children are investigated. This study therefore used data from the 2014 Ghana Demographic and Health Survey to investigate the socio-economic determinants of child health status in Ghana by employing the binary probit model. The study revealed that, Ewe, Grusi, Muslim and Christian children, children from urban areas, Greater Accra, Northern, Ashanti, Upper east, Eastern and Central regions, were more probable to contract cough. Also children with uneducated mothers, those whose mothers had uneducated partners as well as those whose mothers had no health insurance were revealed to be more likely to be anaemic. Further, male children and children from non-wealthy households were revealed to be more likely to have suffered diarrhoea, fever and anaemia. Also children with employed mothers and those with mothers with big distance challenges to seek care were found to be more likely to have fever. These findings, point out the essence of socio-economic factors to child health outcomes and hence the need to be given attention in child health survival interventions in Ghana.
\end{abstract}

Keywords: Child Health Status; Socio-Economic Factors; Diarrhoea; Anaemia; Cough; Fever; Ghana

\section{Introduction}

The Health of Children sends signals about the strength of the future human capital base of any nation and hence economic growth and development. Therefore it is not surprising that tackling the issue of improving the health of children is a public health concern globally and hence the sustainable development goal (SDG) 3.2 which aims at reducing the mortality of children less than five years to 25 deaths per thousand live births by 2030 .

Thus the SDG 3.2 became necessary given that, according to the World Health Organization [WHO] (2016), 5.9 million children less than five years of age died in 2015 mostly due to pneumonia, diarrhoea, birth asphyxia and malaria with about 45 Percent of these deaths being associated with Malnutrition.

Further, Sub-Saharan African children are more than fourteen times more likely to die before their fifth birth day relative to those in the developed region (WHO, 2016) and hence it was not surprising that according to the United Nations [UN] (2015), almost half of the deaths in children less than five years of age in 2015 occurred in Sub-Saharan Africa.

Ghana as a Sub-Saharan African country has an under-five mortality rate of 60 deaths per thousand live births (Ghana Statistical Service [GSS], Ghana Health Service [GHS] \& ICF International, 2015). In addition, Malaria which has fever as one of its major signs, is a public health problem in Ghana with children being one of the most vulnerable groups. Also Pneumonia which has cough as some of its symptoms combined with some respiratory tract infections are major killers of younger children in Ghana (GSS, GHS, \& ICF International, 2015). Moreover, it has been reported that the death of children in Ghana that can be attributed to diarrhoea and pneumonia significantly increased in the 2012-2013 period (GHS, n.d). Also, the presence of the anaemia control programme in Ghana, tells us about the significance of tackling anaemia to the health of the entire population in Ghana which includes child health. Therefore it was not surprising that the GSS, GHS, \& ICF International (2015) contend that $66 \%$ of children in Ghana are anaemic.

Based on the above, this study therefore investigated how socioeconomic factors determine the health status (Fever, Cough, Diarrhoea and Anaemia) of children in Ghana. This would help bring out the factors that are paramount to child health and hence inform policy makers on how to improve upon the current child mortality rate in Ghana in our drive towards achieving the SDG 3.2.

\section{Literature review}

The main theoretical basis of the work was based on the work of Grossman (1999) which basically tells us that individuals are the producers of health and hence certain factors enter the health production function as inputs. The model points out how factors such as age, education and income affect the health production function. However, to identify most of the socio-economic factors with regard to child health, the model of Mosley and Chen (1984) is of much relevance. The framework of Mosley and Chen (1984) points out how socio-economic factors broadly grouped as Individual-level indicators or variables: Parental productivity (skill, education), attitudes, traditions or cultures or norms; Householdlevel Indicators or variables: income/wealth e.t.c and Communitylevel indicators or variables: health system, ecological setting and political economy work through some proximate determinants such as birth interval, age e.t.c to affect child health or survival. On the related works, Escobar et al. (2015) in Brazil revealed in addition to other factors that children who were younger, suffering under nutrition, with low maternal education, with lower household socioeconomic status and with another child suffering diarrhoea in the household had higher risk of Diarrhoea. Fakir and 
Khan (2015) in Bangladesh found per capita income to improve the health status of children but not household assets. Further, better maternal literacy was revealed to tweak the health of male children at the cost of female children and in addition children with elderly (older) siblings were revealed to have better nutritional status. Urke and Mittelmark (2015) found intimate partner violence to have a weak but unwavering influence on signs of illness in Peru and Bolivia but not in Colombia after restraining (controlling) childcare. Kadam, Gowri, and Thirumugam (2013) in India found infant health, mortality and morbidity to be determined by household income, knowledge and education of parents, mother's health pre and during pregnancy, family structure, environmental factors such as hygiene and existence and quality of health services. Joshi, Gupta, Joshi and Vipul (2011) found a high significant association between maternal factors such as dietary knowledge, monthly per-capita income, literacy, occupation and child nutrition in Nepal.

With regard to Ghana, Quansah, Ohene, Norman, Mireku and Karikari (2016) revealed the major determinants of child health to be family income, place of residence, maternal education and high dependency (multiparousity) using a qualitative review of published articles. Fosu-Brefo and Arthur (2015) revealed that early breast feeding immensely impact child health. In addition they found that ages of the child and mother, mother's education, wealth of the household and child's size at birth had significan influences on child health in Ghana. Aheto, Keegan, Taylor and Diggle (2015) found increased risk of malnutrition among children to be linked with multiple births, unavailability of toilet facilities, lengthy breast feeding period, small birth size, poverty, mothers without national health insurance and history of diarrhoea episodes. Conversely, a rise in maternal body mass index and years of education were found to be linked with decreased malnutrition Abubakari, Kynast-Wolf, and Jahn (2015) among other findings revealed that female infants, rural mother's and mothers with diarrhoea episodes during pregnancy were associated with low birth weight in the Northern region of Ghana. Amugsi et al. (2015) among other findings revealed older children to have a higher risk of getting cough and diarrhoea relative to younger children in Ghana. Amugsi, Mittelmark, Lartey, Matanda, and Urke (2014) revealed that maternal weight, the number of children less than five years, place of residence and wealth index, child's age and mother's age to be immensely linked with height-for-age Z-scores (Children's Growth) in Ghana. Borbor, Kumi-Kyereme, Yendaw and Adu-Opong (2014) revealed that, younger children, children from poor households, with higher household size, with lesser paternal and maternal education, with younger mothers and from a rural area were more likely to have anaemia. Egbi et al. (2014) revealed among other findings that, more females had anaemia as compared to males in the Volta region of Ghana. Dwumoh, Essuman and Afagbedzi (2014), Zere, Kirigia, Duale and Akazili (2012) and Hong (2007) have also conducted similar studies on Ghana.

However, among all the studies above that had nationwide representation, none of them used data that is more current as the one used by this study (the 2014 Ghana Demographic and Health Survey). Thus this study would help bring to light the most current factors that determine child health status in Ghana and hence aiding in our drive towards ameliorating the child mortality rate in Ghana which is far above the SDG 3.2.

\section{Methods}

\subsection{Data}

The study utilised data from the 2014 Ghana Demographic and Health Survey ([GDHS], the most recent nationally representative demographic and health survey) which was a cross-sectional survey carried out by the Ghana Statistical Service, the Ghana Health
Service and host of other partners from early September 2014 to mid-December, 2014. During the survey, the mothers or caregivers of children less than five years of age were asked as to whether the child suffered from cough, diarrhoea and fever in the past 14 days or 24 hours before the survey. However, there was no child with any of the ailments in the previous 24 hours before the survey. Therefore this study recoded these health status proxies as 1 , if a child had fever or cough or diarrhoea in the past 14 days before the survey and 0 if not.

With regards to anaemia testing during the 2014 GDHS, it was done by using the haemoglobin level in the blood of children. Thus using sterile and disposable instruments, a drip of capillary blood was taken with a finger prink and the HemoCue photometer system was used to measure the Haemoglobin concentration and hence children with haemoglobin level lower than $11.0 \mathrm{~g} / \mathrm{dl}$ were considered anaemic. In the case of anaemia testing, the data covered children who were present, whose parents consented and had haemoglobin results that constituted plausible data (GSS, GHS, \& ICF International, 2015).

In the original data, anaemia level in children was coded as 1 (severe), 2 (moderate), 3 (mild) and 4 (not anaemic). This study however, recoded it by converting 1,2, and 3 to 1 (anaemic) and 4 was recoded to 0 (not anaemic).

\subsection{Model}

Since the health status proxies (fever, cough, diarrhoea and anaemia) were coded as $1 / 0$, it means they were all dichotomous. Thus each of these proxies was a dependent variable. Given the dichotomous or binary nature of the dependent variables, the study adopted the binary probit model as the empirical model of estimation. Therefore we specify a simplified model as:

$\mathrm{H}=\underline{\mathrm{U} M}+\mathrm{bC}+\not \mathrm{S}+\mu$

Where H (Health Status), represents the likelihood that a child suffered a particular ailment. $\mathrm{M}$ is mother's and partner's characteristics such as age, education, employment e.t.c, $\mathrm{C}$ shows child characteristics such as sex, age and birth order and $\mathrm{S}$ shows other socio-economic variables such as region, ethnicity, household wealth status, residence type, e.t.c., $U, \square$, and $x$ are vector of parameters of the explanatory variables and $\mu$ is the disturbance term.

In this study all don't know responses in the data were treated as missing values and all categorical explanatory variables were treated as dummy variables. It must be stated that, marital status, religion and wealth status were recoded as applied in this study. The Average marginal effects (AMEs) which is seen by many researchers to be superior to the Marginal effects at the means (MEM) were reported since marginal effects give more intuitive meanings to explanatory variables as Williams (2012) contends.

\section{Results and discussion}

Bivariate Analyses (Descriptive Statistics with Pearson Chi Square).

In Table 1 can be seen the distribution of the various categorical explanatory variables with regards to the health status (Diarrhoea, Fever, Cough and Anaemia) of children. Also the Pearson chi square showed whether there were significant relationships between the various explanatory variables and child health status. The result showed that there were significant association between child health status (Diarrhoea, Fever, Cough and Anaemia) and region, religion, ethnicity, mother's education, partner's education and household wealth status. Further, there were significant association between residence and all the child health proxies apart from Diarrhoea. The results further showed significant association between Diarrhoea, Fever and Anaemia status of children and 
money to seek medical care by mother, distance to seek medical care by mother and sex of child. Mother's health insurance also was revealed to have significant relationships with fever and anaemia status of children. Also as can be seen, $11.84 \%$ and $12.30 \%$ of urban and rural children were revealed to have suffered from diarrhoea respectively. Also $71.11 \%$ and $67.95 \%$ of male and female children were found to have suffered from anaemia respec- tively. With regards to religious background, it can be seen that, $14.09 \%, 18.17 \%$ and $13.21 \%$ of Christian, Muslim (Islam) and traditional/ spiritualist/no religion faiths children suffered from fever respectively. Moreover, $74.80 \%$ and $55.69 \%$ of non-rich and rich (wealthy) household children were found to have suffered from anaemia respectively.

Table 1: Bivariate Analyses of Fever, Cough and Diarrhoea in Children and Categorical Explanatory Variables

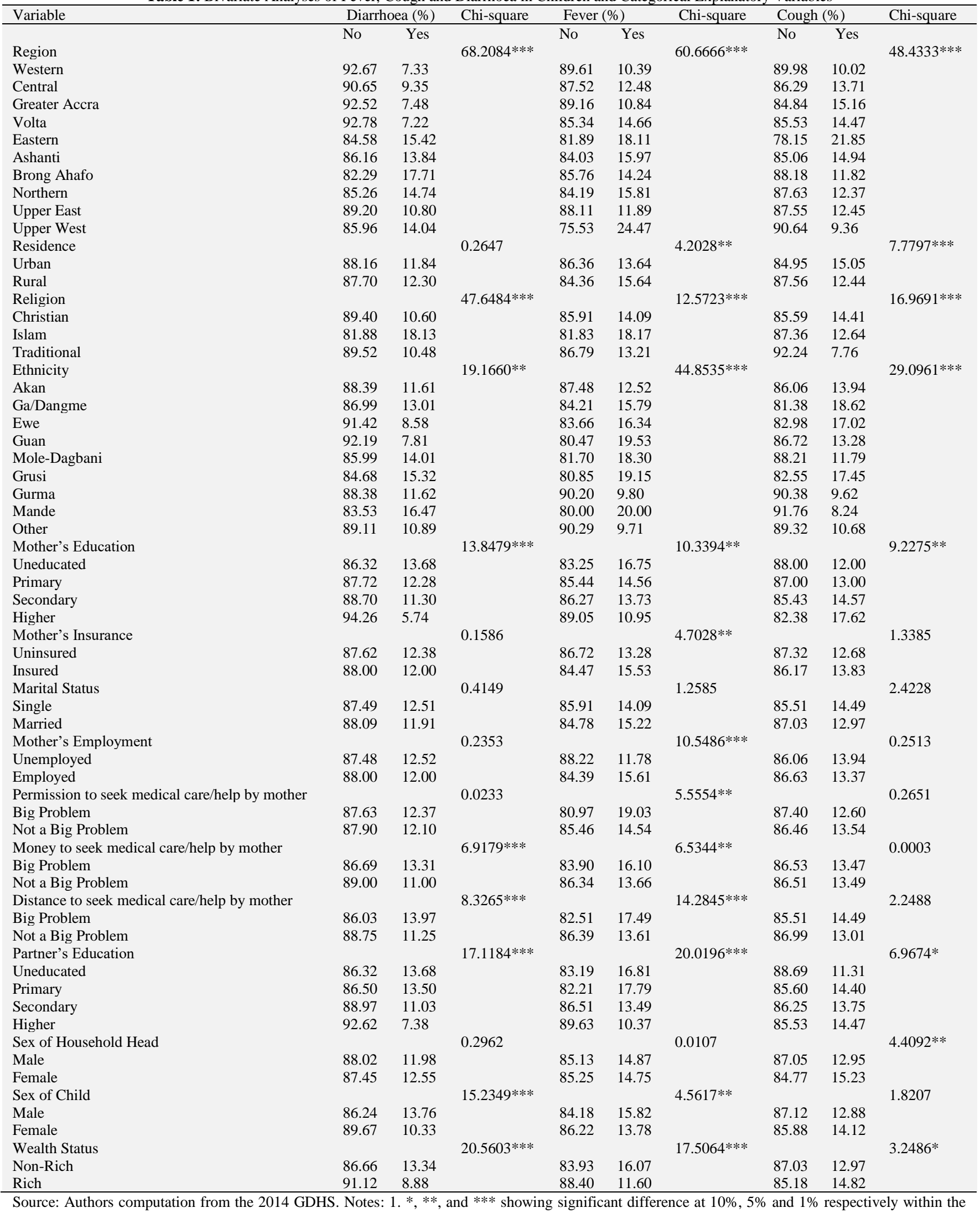

predictor and fever, cough and diarrhoea among children in Ghana. 2. Traditional in this study means traditional/ spiritualist and no religion. 
Table 2: Bivariate Analyses of Anaemia in Children and Categorical Explanatory Variables

\begin{tabular}{|c|c|c|c|c|c|c|c|}
\hline \multirow[t]{2}{*}{ Variable } & \multicolumn{2}{|c|}{ Anaemia $(\%)$} & \multirow[t]{2}{*}{ Chi-square } & \multirow[t]{2}{*}{ Variable } & \multicolumn{2}{|c|}{ Anaemia (\%) } & \multirow[t]{2}{*}{ Chi-square } \\
\hline & No & Yes & & & No & Yes & \\
\hline Region & & & $89.0549 * * *$ & Mother's Education & & & $90.0295 * * *$ \\
\hline Western & 31.98 & 68.02 & & Uneducated & 20.23 & 79.77 & \\
\hline Greater Accra & 40.00 & 60.00 & & Secondary & 38.13 & 61.88 & \\
\hline Volta & 29.95 & 70.05 & & Higher & 54.79 & 45.21 & \\
\hline Eastern & 32.04 & 67.96 & & Mother's Insurance & & & $11.1827 * * *$ \\
\hline Ashanti & 47.44 & 52.56 & & Uninsured & 25.76 & 74.24 & \\
\hline Northern & 15.12 & 84.88 & & Marital Status & & & 0.0561 \\
\hline Upper East & 27.06 & 72.94 & & Single & 30.08 & 69.92 & \\
\hline Upper West & 27.41 & 72.59 & & Married & 30.56 & 69.44 & \\
\hline Residence & & & $35.6130 * * *$ & Mother's Employment & & & 0.5367 \\
\hline Urban & 37.27 & 62.73 & & Unemployed & 31.90 & 68.10 & \\
\hline Rural & 25.80 & 74.20 & & Employed & 30.12 & 69.88 & \\
\hline Religion & & & $46.0045^{* * *}$ & Permission to seek medical care/help by mother & & & 1.2235 \\
\hline Christian & 34.43 & 65.57 & & Big Problem & 26.35 & 73.65 & \\
\hline Traditional & 16.06 & 83.94 & & Money to seek medical care/help by mother & & & $29.5152 * * *$ \\
\hline Ethnicity & & & $67.6267 * * *$ & Big Problem & 25.09 & 74.91 & \\
\hline Akan & 37.89 & 62.11 & & Not a Big Problem & 35.32 & 64.68 & \\
\hline $\mathrm{Ga} /$ Dangme & 33.68 & 66.32 & & Distance to seek medical care/help by mother & & & $17.5654 * * *$ \\
\hline Ewe & 31.75 & 68.25 & & Big Problem & 24.57 & 75.43 & \\
\hline Guan & 29.51 & 70.49 & & Not a Big Problem & 33.07 & 66.93 & \\
\hline Mole-Dagbani & 25.40 & 74.60 & & Partner's Education & & & $86.3314 * * *$ \\
\hline Grusi & 32.46 & 67.54 & & Uneducated & 18.77 & 81.23 & \\
\hline Gurma & 13.98 & 86.02 & & Primary & 25.09 & 74.91 & \\
\hline Mande & 23.33 & 76.67 & & Secondary & 36.28 & 63.72 & \\
\hline Other & 15.38 & 84.62 & & Higher & 45.36 & 54.64 & \\
\hline Sex of Household Head & & & 0.3450 & Sex of Child & & & $2.8060 *$ \\
\hline Male & 30.10 & 69.90 & & Male & 28.89 & 71.11 & \\
\hline Female & 31.41 & 68.59 & & Female & 32.05 & 67.95 & \\
\hline Wealth Status & & & $81.6175^{* * *}$ & & & & \\
\hline Non-Rich & 25.20 & 74.80 & & & & & \\
\hline Rich & 44.31 & 55.69 & & & & & \\
\hline
\end{tabular}

\subsection{Regression results}

This sub-section discussed the socio-economic factors which influence the health status of children in Ghana using the binary probit regression model.

Table 3: Probit Regressions on Socio-Economic Factors and Child Health Status in Ghana

\begin{tabular}{|c|c|c|c|c|}
\hline Dependent Variable & Diarrhoea & Fever & Cough & Anaemia \\
\hline $\begin{array}{l}\text { Independent Variable } \\
\text { Region(Ref: Upper } \\
\text { West) }\end{array}$ & AME & AME & AME & AME \\
\hline Western & $-.0532818 * *$ & $-.0920421 * * *$ & .0118388 & .0405946 \\
\hline Central & -.0407197 & $-.0553546^{*}$ & $.051492 * *$ & .0631523 \\
\hline Greater Accra & $-.0450493 *$ & $-.0806176^{* *}$ & $.0433028 *$ & -.018447 \\
\hline Volta & $-.0451094 *$ & -.0546221 & .0413917 & -.0316564 \\
\hline Eastern & .0164755 & -.0136191 & $.1179508 * * *$ & -.0136766 \\
\hline Ashanti & .0185166 & -.0152488 & $.0649906^{* * *}$ & $-.1122619 * *$ \\
\hline Brong Ahafo & .0339945 & $-.0640671 * *$ & .0330037 & -.0414921 \\
\hline Northern & .0151946 & -.0218242 & $.0625446 * * *$ & .0561503 \\
\hline Upper East & -.0202869 & $-.0962828 * * *$ & $.0354082 *$ & .0011709 \\
\hline $\begin{array}{l}\text { Residence } \\
\text { (Ref:Rural) }\end{array}$ & & & & \\
\hline $\begin{array}{l}\text { Urban } \\
\text { Religion (Ref: Tradi- } \\
\text { tional) }\end{array}$ & .0183442 & .0096067 & $.0257733^{* * *}$ & .0117291 \\
\hline Christian & .0016575 & .0223184 & $.0539449 * * *$ & $-.0885593 * *$ \\
\hline $\begin{array}{l}\text { Islam } \\
\text { Ethnicity(Ref: other) }\end{array}$ & $.066625 * * *$ & .0180751 & $.0451376 * *$ & -.0124038 \\
\hline Akan & .0359486 & .0095064 & .0438425 & $-.1242696^{*}$ \\
\hline $\mathrm{Ga} /$ Dangme & .0448398 & .0462611 & .0452426 & -.0524946 \\
\hline Ewe & .014563 & .0455015 & $.0680842 *$ & -.0820207 \\
\hline Guan & -.0392575 & .0771444 & .0458927 & -.1424717 \\
\hline Mole-Dagbani & .0049265 & .0438047 & .0331346 & $-.1407937 * *$ \\
\hline Grusi & .0347619 & .0585399 & $.106202 * *$ & $-.1629429 * *$ \\
\hline Gurma & -.0051489 & -.0489709 & -.0023502 & -.0484388 \\
\hline Mande & -.001192 & .0735804 & -.0011499 & -.1423818 \\
\hline $\begin{array}{l}\text { Mother's Education } \\
\text { (Ref: Uneducated) }\end{array}$ & & & & \\
\hline
\end{tabular}




\begin{tabular}{|c|c|c|c|c|}
\hline Primary & -.0023311 & -.0076655 & -.0189157 & -.0473756 \\
\hline Secondary & -.0090166 & -.002212 & -.0110587 & $-.0696152 * *$ \\
\hline Higher & -.0307876 & -.0237178 & .0146928 & $-.1435621 * *$ \\
\hline \multicolumn{5}{|l|}{$\begin{array}{l}\text { Mother's Insurance(Ref: } \\
\text { Uninsured) }\end{array}$} \\
\hline & \multicolumn{4}{|c|}{ Marital Status (Ref: } \\
\hline $\begin{array}{l}\text { Married } \\
\text { Mother's Employment } \\
\text { (Ref: Unemployed) }\end{array}$ & -.0044069 & .0002726 & -.0005962 & -.0004939 \\
\hline $\begin{array}{l}\text { Employed } \\
\text { Permission to Seek } \\
\text { Medical Care by Moth- } \\
\text { er( Ref: Not a big prob- } \\
\text { lem) }\end{array}$ & .0089974 & $.0471955^{* * *}$ & .0150347 & .0290478 \\
\hline $\begin{array}{l}\text { Big Problem } \\
\text { Money to Seek Medical } \\
\text { Care by Mother( Ref: } \\
\text { Not a big problem) }\end{array}$ & -.0122711 & .0280066 & .0007322 & -.023274 \\
\hline $\begin{array}{l}\text { Big Problem } \\
\text { Distance to Seek Medi- } \\
\text { cal Care by Mother( Ref: } \\
\text { Not a big problem) }\end{array}$ & .0076797 & -.0065604 & .0018146 & .0359314 \\
\hline $\begin{array}{l}\text { Big Problem } \\
\text { Partner's Education } \\
\text { (Ref: Uneducated) }\end{array}$ & .0084423 & $.0229874 *$ & .0200159 & -.0082151 \\
\hline Primary & .0088253 & .0207113 & .0114248 & -.0031998 \\
\hline Secondary & -.0021563 & -.0114361 & -.0089943 & $-.0614205^{* *}$ \\
\hline Higher & -.0267544 & $-.0374555^{*}$ & -.0176655 & -.0764585 \\
\hline $\begin{array}{l}\text { Sex of Household } \\
\text { head(Ref: Female Head) }\end{array}$ & & & & \\
\hline $\begin{array}{l}\text { Male head } \\
\text { Sex of Child (Ref: Fe- } \\
\text { male) }\end{array}$ & .0019632 & -.0026913 & -.0059958 & -.0379127 \\
\hline $\begin{array}{l}\text { Male Child } \\
\text { Wealth(Ref: Non-Rich) }\end{array}$ & $.0382883 * * *$ & $.0197648 * *$ & -.0136338 & $.0513151^{* * *}$ \\
\hline Mother's Age & .0000505 & $.0022997 *$ & .0002103 & $-.0045687 * *$ \\
\hline Age of Household Head & $-.0007123 *$ & -.0004081 & $-.0008065^{*}$ & -.0010875 \\
\hline Birth Order of Child & .0020555 & -.0020639 & -.0041992 & $.0176767 * *$ \\
\hline Childs Age & $-.0199801 * * *$ & .0041434 & $-.0084934 * *$ & $-.0569939 * * *$ \\
\hline & $\mathrm{N}=5100$ & $\mathrm{~N}=5109$ & $\mathrm{~N}=5108$ & $\mathrm{~N}=2220$ \\
\hline & Prob $>$ chi $2=.0000$ & Prob $>$ chi $2=.0000$ & Prob $>$ chi $2=.0000$ & Prob $>$ chi $2=.0000$ \\
\hline
\end{tabular}

Source: Authors computation from the 2014 GDHS. Notes: $1 . * * * \mathrm{P}$-value<.01, **P-value<.05, *P-value<.1. 2. Traditional in this study means traditional/ spiritualist/ no religion.

From the results on diarrhoea, on average children from the Western, Volta and Greater regions were all $5 \%$ less probable to get diarrhoea relative to those in the Upper West region. These send signals on regional differentials in the health status (diarrhoea status) of children in Ghana. Also on average, Muslim children and male children were $7 \%$ and $4 \%$ more probable to have diarrhoea relative to those from Spiritualist/Traditional/No religion faiths and female children respectively. The findings of male children is in line with that of Darteh et al. (2014) who revealed stunting to be higher among males than females in Ghana. This can be due to the perception of people that male children are naturally stronger relative to female children and hence may not be given much care which might make them more susceptible to diseases. In addition, wealthy households' children were $4 \%$ less probable to suffer diarrhoea relative to those from non-wealthy homes. This concurs with the findings of Escobar et al. (2015) in Brazil. The reason is that wealthy households are more capable to afford inputs of child health and cleaner water, environment, etc as compared to non-wealthy households and hence translating in to a good health for wealthy households' children.

In addition, on average, a yearly increase in the ages of the household head and that of the child were revealed to decrease by. $07 \%$ and $2 \%$ the probability that a child suffered from diarrhoea respectively. This is because older people might have acquired so much experience concerning disease avoidance and healthy living and hence would be efficient producers of child health as compared to younger individuals. The finding on child's age flouts that of Fosu-Brefo and Arthur (2015) who revealed rising child's age to be linked with lesser health (height-for-age $\mathrm{Z}$ score) and Amugsi et al. (2015) in the case of diarrhoea among children in Ghana. The reason could be that older children might have developed stronger immune systems as they grow and hence making them less prone to diseases.

With regards to Fever, on the average, children from the Western, Greater Accra, Central, Upper East and Brong Ahafo regions were less likely to suffer from fever two weeks prior the survey by $9 \%$, $8 \%, 6 \%, 10 \%$ and $6 \%$ respectively relative to those in the Upper West region. The result on the Western region is similar to that of Nyarko and Cobblah (2014).

Surprisingly, Children with employed mothers were 5\% more likely to have suffered from fever relative to those with unemployed mothers. This might be that; employed mothers do not have enough time and care for their children as they give so much attention to their jobs.

Also children of mothers with big problems in terms of distance to seek self-medical help were $2 \%$ more likely to suffer from fever relative to children whose mothers had no big problems with distance to seek self-medical care. This implies big challenges with distance to seek care for mothers could prevent them from sending children to health facilities or centres where usually child health education and child health inputs such as immunisation are rendered and hence may affect the health of their children negatively. Furthermore, Children with mothers whose partners had higher level of education were $4 \%$ less likely to have suffered from fever relative to children with mothers whose partners had no education. This is because; the educated are better efficient producers of child health relative to the uneducated. This concurs with the result of Borbor et al. (2014) who found lesser paternal education to be 
linked with higher probability of anaemia among children in Ghana. Also male children were revealed to be $2 \%$ more probable to suffer from fever relative to female children. This is similar to the results of Darteh et al. (2014) who found stunting to be more among males than females. The explanation under diarrhoea still applies here.

Also children form wealthy homes were found to be $4 \%$ less probable to suffer from fever relative to those from non-wealthy homes. Last but not the least, a yearly rise in the age of the mother was found to increase the likelihood of children suffering fever by $.2 \%$. This might be that, older mothers have many children under their care and hence would not have much attention for younger children resulting in poor health status. It might also be that older mothers (who are more probable to have older children) may hand over the care of younger children to older children and since they (older children) lack enough experience in taking good care of these younger children, may result in bad health. This conflicts the findings of Fosu-Brefo and Arthur (2015) who revealed increasing mother's age to be linked with higher child health (height-for-age $\mathrm{Z}$ score) in Ghana.

Concerning Cough, on the average, Central, Eastern, Greater Accra, Ashanti, Upper East and Northern region children, were found to be $5 \%, 12 \%, 4 \%, 6 \%, 4 \%$ and $6 \%$ respectively more probable to have suffered cough relative to those in the Upper West region (reference group). Further, urban children were revealed to be $3 \%$ more probable to suffer from cough relative to rural children. This possibly could be the higher pollution levels in urban areas because of heavy industrial and vehicular emissions and hence leading to more vulnerability to cough among urban children. This is contrary to the findings of Borbor et al. (2014) who revealed children from rural areas to be more likely to get anaemia in Ghana. Also Christian and Islamic faiths children were 5\% more probable to have cough relative to those from the Traditional/Spiritualist/No religion faith. Further on ethnicity, Ewe and Grusi children were $7 \%$ and $11 \%$ more probable to have cough relative to children in the other ethnic groups. This reinforces the essence of ethnicity as a proxy for socio-cultural factors and how they influence child health. Last but not the least, a yearly increase in the ages of the child and that of the household head decreased the likelihood of children contracting cough by $.8 \%$ and $.08 \%$ respectively. The result on child's age is not in line with that of Amugsi et al. (2015) who found older children to have a higher risk of contracting cough relative to younger children in Ghana.

Concerning Anaemia, Ashanti region children were found to be $11 \%$ less probable to suffer from anaemia relative to those in the Upper West region. Also on average, Christian children were 9\% less probable to suffer from anaemia relative to children from Traditional/Spiritualist/No religion background.

On ethnicity, Akan, Grusi and Mole-Dagbani children were 12\%, $16 \%$ and $14 \%$ respectively less likely to suffer from anaemia relative to those in the other ethnic groups.

Also on average, children whose mothers had higher and secondary education were $14 \%$ and $7 \%$ respectively less likely to suffer from anaemia as compared to children with uneducated mothers. This is in line with the result of Aheto et al. (2015) who revealed increasing maternal years of education to be linked with decreased risk of malnutrition, Fosu-Brefo and Arthur (2015) who revealed that mother's education (tertiary level) had positive influence on child health (height-for-age Z-score), Joshi et al. (2011) who found a high significant linkage between child nutrition and maternal literacy in Nepal and Borbor et al. (2014) who revealed children with lower maternal education (uneducated and primary education), to be more probable to get anaemia.

Furthermore, children whose mothers had health insurance were revealed to be $4 \%$ less likely to suffer from anaemia relative to those with uninsured mothers. This is in line with the result of Aheto et al. (2015) who revealed the non-existence of maternal health insurance to be linked with a higher risk of malnutrition. The reason is that, health insurance makes medical care relatively cheaper and hence mothers would utilise for themselves and their children especially in the case of the national health insurance scheme in Ghana where there is free health insurance registration for children and pregnant women. Also since mothers with health insurance are more likely comparatively to visit health facilities, they may get health education on good child health practices as compared to their uninsured counterparts.

In addition, on average, children with mothers whose partners had secondary education were $6 \%$ less probable to suffer from anaemia relative to children with mothers whose partners had no education.

Also male children were revealed to be $5 \%$ more probable to suffer from anaemia relative to female children. This contradicts the results of Egbi et al. (2014) who revealed females to be more linked with anaemia rather. This finding is very disturbing given that it was observed under both diarrhoea and fever.

Also wealthy households' children were $6 \%$ less probable to suffer anaemia relative to those from non-wealthy households. This concurs with the results of Aheto et al. (2015) who revealed poverty to be linked with increased risk of malnutrition in children, Fosu-Brefo and Arthur (2015) in the case age-for-height Z-score and Borbor et al. (2014) who revealed children from poor households to be more likely to get anaemia. Again the result is similar to those observed under both diarrhoea and fever above.

Also on average, a yearly increase in the ages of the mother and that of the child decreased the probability that a child contracted anaemia by $.5 \%$ and $6 \%$ respectively. These findings are similar to those of Borbor et al. (2014) in Ghana. This might be that older mothers have given several births and therefore have gained enough experience in child care practices. The finding on child's age is in line with the results on diarrhoea and cough above.

Last but not the least, a unit rise in child's birth order was revealed to increase the probability of suffering from anaemia by $2 \%$. This might be that, less experienced older children are left with the responsibility of catering for younger children. Also it could be that caregivers or mothers have many children and hence may not have enough attention for their younger (those with higher birth order) children who need lots of care and attention.

\section{Conclusion}

Based on the findings, the paper can conclude that residence, region, ethnicity, wealth status, mother's employment status, religion, mother's health insurance, mother's education, partner's education, distance to seek medical care by mother, sex of the child, age of the household head, maternal age, child's age and birth order of the child are the main determinants of the health status of children in Ghana.

Therefore intensifying child health interventions in regions without neglecting urban areas could be an effective tool towards improving child health status in Ghana. This is because children from urban areas, Greater Accra, Northern, Ashanti, Upper east, Eastern and Central regions were more probable to contract cough.

Targeting religious faiths and ethnic groups with regards to education on better child health practices should be embarked upon since Muslim children were more likely to have suffered from cough and diarrhoea whiles children from the Traditional/no religion or spiritualist faiths on one hand and Ewe, Grusi, Christian children on another hand were more probable to suffer from anaemia and cough respectively. Such education drives should point out the need for all children irrespective of their sex to be given better health attention since male children were more likely to contract fever, diarrhoea and anaemia relative to their female counterparts.

Targeting the uneducated mothers and partners with regards to better child health practices can also be instituted. As a long term goal, opening education opportunities for all, especially up to at 
least the secondary level could help in bettering child health outcomes since maternal education up to the secondary and higher levels and paternal education up to the secondary level were found to reduce the likelihood of anaemia in Children. Also higher paternal level of education was revealed to reduce the likelihood of fever in children.

Strengthening the free maternal health insurance scheme and encouraging women without health insurance to register should be instituted since maternal health insurance was revealed to decrease the probability of anaemia in children.

Policies that are geared towards given enough maternal leave for employed nursing mothers can be embarked upon given that children with employed mothers were more likely to suffer from fever relative to those with unemployed mothers. Alternatively, better regulated child care homes could be established for employed mothers to send their children for proper care if their jobs would not give them enough time.

Finally, Poverty reduction strategies as a long term goal as well as aiding non-wealthy households with regards to better child health practices should be encouraged since children from wealthy households were revealed to be less likely to contract diarrhoea, fever and anaemia relative to those from non-wealthy homes.

\section{Acknowledgement}

We are being thankful to the DHS Program for the data

\section{Conflicts of interests}

None

\section{References}

[1] Abubakari A, Kynast-Wolf G, \& Jahn A (2015) Maternal Determinants of Birth Weight in Northern Ghana. PLoS ONE 10(8), e0135641. https://doi.org/10.1371/journal.pone.0135641.

[2] Aheto KJM, Keegan JT, Taylor, MB, \& Diggle JP (2015) Childhood Malnutrition and Its Determinants among Under-Five Children in Ghana. Paediatric and Perinatal Epidemiology, 29,552-61. https://doi.org/10.1111/ppe.12222.

[3] Amugsi AD, Aborigo AR, Oduro RA, Asoala V, Awine T \& Amenga-Etego L (2015) Socio-demographic and environmental determinants of infectious disease morbidity in children under 5 years in Ghana. Glob Health Action, 8(29349). Retrieved from https://doi.org/10.3402/gha.v8.29349

[4] Amugsi AD, Mittelmark BM, Lartey A, Matanda JD, \& Urke BH (2014) Influence of childcare practices on nutritional status of Ghanaian children: a regression analysis of the Ghana Demographic and Health Surveys. BMJ Open 2014, 4:e05340.

[5] Borbor MF, Kumi-Kyereme A, Yendaw E, \& Adu-Opong A (2014) A Study of the Determinants of Anaemia among Under-Five Children in Ghana. International Journal of Development Research, 4(4), 858-867.

[6] Darteh MKE, Acquah E, \& Kumi-Kyereme A (2014) Correlates of stunting among children in Ghana"' BMC Public Health, 14(504). Retrieved from http://www.biomedcentral.com/1471-2458/14/504.

[7] Dwumoh D, Essuman EE, \& Afagbedzi KS (2014) Determinant of factors associated with child health outcomes and service utilization in Ghana: multiple indicator cluster survey conducted in 2011. Archives of Public Health, 72(42). Retrieved from http://www.archpublichealth.com/content/72/1/42.

[8] Egbi G, Steiner-Asiedu M, Kwesi SF, Ayi I, Ofosu W, Setorglo J...\& Armar-Klemesu M (2014) Anaemia among school children older than five years in the Volta Region of Ghana. Pan Afr Med J. 17(Suppl 1), 10

[9] Escobar LA, Coimbra AEC, Welch RJ, Horta LB, Santos VR, \& Cardoso, MA (2015) Diarrhea and health inequity among Indigenous children in Brazil: results from the First National Survey of Indigenous People's Health and Nutrition. BMC Public Health, 15(191). https://doi.org/10.1186/s12889-015-1534-7.

[10] Fakir SMA, \& Khan RWM (2015) Determinants of malnutrition among urban slum children in Bangladesh. Health Economics Review 5 (22). https://doi.org/10.1186/s13561-015-0059-1.
[11] Fosu-Brefo R \& Arthur E (2015) Effect of timely initiation of breastfeeding on child health in Ghana. Health Economics Review, 5(8). https://doi.org/10.1186/s13561-015-0044-8.

[12] Ghana Health Service (n.d.). 2014 Family Health Annual Report.

[13] Ghana Statistical Service, Ghana Health Service, \& ICF International. Ghana Demographic and Health Survey 2014. Rockville, Maryland, USA: GSS, GHS, and ICF International, 2015.

[14] Grossman M (1999) the Human Capital Model and the Demand for Health. NBER Working Paper No. 7078.

[15] Hong R (2007) Effect of economic inequality on chronic childhood undernutrition in Ghana. Public Health Nutrition, 10(4), 371-378. https://doi.org/10.1017/S1368980007226035.

[16] Joshi HS, Gupta R, Joshi MC, \& Mahajan V (2011) Determinants of Nutritional Status of School Children - A Cross Sectional Study in the Western Region of Nepal. National Journal of Integrated Research in Medicine, 2(1).

[17] Kadam BS, Gowri V, \& Thirumugam M (2013) Determinants of Health Status of Infants in Nashik City, India. Lap LAMBERT Academic Publishing-ISBN: 978-3-659-42794-7.

[18] Mosley HW, \& Chen CL (1984) an analytic framework for the study of child survival in developing countries. Bulletin of the World Health Organization 2003, 81 (2, Extracted from Population and Development Review 10, Suppl: 25-45. https://doi.org/10.2307/2807954.

[19] United Nations (2015) The Millennium Development Goals Report 2015.

[20] Quansah E, Ohene LA, Norman L, Mireku MO, \& Karikari TK (2016) Social Factors Influencing Child Health in Ghana. PLoS ONE 11(1): e0145401. https://doi.org/10.1371/journal.pone.0145401.

[21] Urke BH, \& Mittelmark BM (2015) Associations between intimate partner violence, childcare practices and infant health: findings from Demographic and Health Surveys in Bolivia, Colombia and Peru. BMC Public Health, 15(819). https://doi.org/10.1186/s12889015-2144-0.

[22] Williams R (2012) Using the margins command to estimate and interpret adjusted predictions and marginal effects. The Stata Journal , 12 (2), 308-331.

[23] World Health Organization (2016) Children: Reducing Mortality. Fact Sheet updated September, 2016. Accessed from: http://www.who.int/mediacentre/factsheets/fs178/en/ on 22/05/2017

[24] Zere E, Kirigia MJ, Duale S, \& Akazili J (2012) Inequities in maternal and child health outcomes and interventions in Ghana. BMC Public Health, (12):252. Retrieved from http://www.biomedcentral.com/1471-2458/12/252. https://doi.org/10.1186/1471-2458-12-252. 